\title{
CVD IL-2/IFNa2b Regimen
}

National Cancer Institute

\section{Source}

National Cancer Institute. CVD IL-2/IFNa2b Regimen. NCI Thesaurus. Code C63785.

A regimen consisting of cisplatin, vinblastine, dacarbazine, interleukin-2 (IL-2) and interferon alfa-2b (IFNa2b) that can be used for the treatment of melanoma. 